\title{
Professor Wilhelm Czermak $\dagger$.
}

Zum letzten Male erscheint in diesem Archiv, das so oft Arbeiten Czermaks gebracht hatte, ein Aufsatz mit der Überschrift seines Namens, aber leider nicht mehr aus seiner Feder. Am 8. Septernber dieses Jahres ist Czermak in vollständiger Kraft und Frische einem Gehirnschlage erlegen, in Lans bei Innsbruck, wo er zur Erholung weilte.

Czermak war schon durch seine Abstammung zum Ärzteberuf prädestiniert. Sein Vater war Professor der Psychiatrie in Graz gewesen, der Bruder seines Vaters war der bekannte Physiologe Czermak. Aber auch die weiteren Vorfahren Czermaks sowohl väterlicher als mütterlicher Seite waren zumeist Ärzte oder selbst Professoren der Medizin gewesen. So schlug er denn diese Laufbahn als fast selbstverständlich ein, obwohl er das Unglück hatte, schon im 14. Lebensjahre seinen Vater zu verlieren. Er absolvierte seine medizinischen Strdien in Graz und wurde dort Assistent an der damals von Blodig geleiteten Augenklinik; von cort kam or an die II. Wiener Augenklinik, an welcher er von 1887 bis 1891 blieb. Während seiner Assistentenzeit hatte er sich habilitiert und wurde 1891 als Professor nach Innsbruck und von dort 1895 nach Prag berufen, wo er bis zu seinem Tode blieb. Er lebte mit einer Tochter des berühmten Rechtslehrers Pfaff in glücklicher, mit drei Kindern gesegneter Ehe.

Dieser kurze Abriss des äusseren Lebenslaufes sagt nichts über das Wesen des Menschen, der diesen Rabmen ausfüllte; es sagt uns höchstens, wie 'weit der Mensch sich nach aussen hin zur-Geltung zu bringen vermochte, aber das Beste im Menschen äussert sich sehr oft überhaupt nicht nach aussen hin. So ist auch viel von den glänzenden Anlagen Czermaks nur den ihm am nächsten stehenden Personen bekannt geworden; sein lebensfroher Sinn, seine Liebe zur Kunst, seine eminente Befähigung für Sprachen. Als in der Wiener Klinik öfter Patienten aus Griechenland gelegen waren, hatte er im $\mathrm{Nu}$ Neugriechisch erlernt gehabt, und sprach es recht geläufig; ebenso 
beschäftigte er sich mit Sanskrit, mit skandinavischen Sprachen, und so hätte Czermak wohl einen vorziglichen Philologen abgegeben, wenn ihn das Schicksal auf diesen Weg gewiesen hätte.

Der genial angelegten Natur Czermaks entsprach es weniger, den feinsten Details nachzuspüren, als vielmehr den Fragen, die er sich stellte, sofort auf den Grund zu gehen, und fast jede seiner Arbeiten wirft daher neues Licht auf den behandelten Gegenstand. Die erste grössere selbständige Arbeit Czermaks war die 1885 exschienene genaue Beschreibung der Zonula Zinnii ${ }^{1}$ ), in welcher die ältere Anschauung von der membranösen Natur der Zonula und von der Existenz eines Canalis Petiti gründlich beseitigt wurde. In einex Analyse von sieben Fällen von Bluterguss in die vordere Kammer'), in welchen nach Resorption des Blutes keine Spuren von Verletzung an der Iris zu sehen gewesen waren, weist er durch scharfsinnige Betrachtungen nach, dass die Blutung nur durch die Eröffnung des Schlemmschen Kanales entstanden sein konnte, und zwar infolge Einreissung des Ligamentum pectinatum. Dass eine solche Verletzung, an die bis dahin niemand gedacht hatte, in der Tat häufig vorkommt, habe ich an zahlreichen anatomischen Präparaten verletzter Augen bestätigt gefunden. Neu und richtig war auch seine Auffassung der Entstehung der Hornhautfisteln ${ }^{3}$ ). Nach der allgemeinen Ansicht sollten sich diese bilden, wenn die Perforationsstelle vor der Pupille liegt, so dass die Iris die Öfnung nicht verstopfen kann; dann krieche das Hornhautepithel in die Öffnung hinein und verhindere deren Schliessung. Als ich begonnen hatte, bei Vorfällen der Iris diese sorgfältig auszuschneiden, so dass nirgends mehr Iris in der Nähe der Durchbruchsöffnung lag, war ich erstaunt, statt der erwarteten Fistelbildung raschen Verschluss der Öffnung zu bekommen. Czermaks Befunde klärten dieses auf: die Fistel entsteht nicht, wenn die Iris die Öffnung ganz frei lässt, sondern wenn sie mit ihrem Pupillarrand sich in die Öffnung legt, ohne sie doch ganz zu verschliessen. Auch handelt es sich bei den Fisteln keineswegs um epithelbekleidete Kanäle, sondern um ein System feiner, verzweigter Hohlräıme und Spalten, welche aus der vorderen Kammer bis unter das Epithel reichen.

Von den weiteren Arbeiten Czermaks seien nur noch diejenigen hervorgehoben, welche sich auf das Glaukom beziehen. Diese Krankheit

i) Dieses Árchiv. Bd. XXXI, 1.

2) Klinische Monatsblätter für Augenheilkunde. 1889.

s) Dieses Archiv. Bd. XXXVI, 2. und Bd. XXXVII, 2. 
war immer das Lieblingsstudium Czermaks gewesen; seine erste Arbeit, gemeinschaftlich mit Prof. Birnbacher ${ }^{1}$ ), beschäftigte sich damit und in den letzten Jahren hatte er reiches Material für eine grössere Arbeit zusammengetragen, von der ihn der vorzeitige Tod abberief. In der ersten Arbeit hatte Czermak zusammen mit seinem Mitarbeiter geglaubt, in den von ihnen konstatierten Veränderungen in der Wand der Wirbelvenen und den dadurch bedingten Veränderungen der Lichtung dieser Venen die Ursache der Drucksteigerung gefunden zu haben. Czermak hat diese Ansicht später fallen gelassen und trat 1897 mit einer andern Erklärung des Glaukoms hervor $^{2}$ ). Er lässt den akuten Glaukomanfall dadurch entstehen, dass in Augen mit seichter Kammer die Irisperipherie an die hintere Hornhautfäche sich anlegt, wenn bei Erweiterung der Pupille die Iris dicker wird. Dieses ist schon vor $\mathrm{Czermak}$ ausgesprochen worden, aber Czermak zeigte genauer als bis dahin geschehen war, wie diese Anlegung geschieht, nämlich nicht mit der dünnen Iriswurzel selbst, sondern mit jener zentral davon gelegenen Stelle, wo die Tris plötzlich dicker wird. Er erklärte auf neue Weise, warum der prodromale Anfall wieder von selbst zurückgeht, indem die Drucksteigerung einen Reiz setzt, wodurch der Sphincter pupillae zur Kontraktion angeregt wird und so die Iriswurzel wieder von der Hornhaut wegzieht.

Czermak war ein Operateur von hervorragender Technik und beschäftigte sich während seiner ganzen ophthalmologischen Tätigkeit immerfort mit einzelnen Operationsproblemen. Eines derselben, welches er immer wieder in Angriff nahm, war die Ausbildung der Staroperation, um ihr grössere Sicherheit des Erfolges, namentlich in bezug auf Wundinfektion und Vorfall der Iris zu geben. Schon als Assistent an der Wiener Augenklinik hatte er versucht, dies durch Vernähung der Extraktionswunde zu stande zu bringen, und er glaubte sein Ziel zuletzt erreicht zu haben, als er 1903 den in Heidelberg versammelten Augenärzten seine subconjunctivale Methode der Extraktion darlegte. Die Kompliziertheit dieser Operationsmethode zeigt, wie wenig technische Schwierigkeiten für Czermak in Betracht kamen.

Die Frucht seiner reichen operativen Erfahrungen an dem grossen Materiale der Prager Klinik und seiner beständigen Beschäftigung mit operativen Fragen ist das Werk über die „Augenärztlichen Operationen", welches vor allen andern Czermaks Lebenswerk darstellt. Er hat es 1893 begonnen und erst 1904 vollendet. Die Übersiedlung

1) Dieses Archiv. Bd. XXXI, 1.

2) Prager medizinische Wochenschrift. 
nach Prag und vor allem die Einrichtung der neuen Klinik daselbst, die unter Czermaks Leitung gebaut wurde, hatte diese Verzögerung verursacht, durch welche es leider geschah, dass zur Zeit, als die letzten Hefte erschienen, die ersten schon längst vergriffen waren und auch nicht mehr dem neuesten Stande der Wissenschaft entsprachen. Czermaks nächste, leider durch den Tod vereitelte Arbeit sollte es sein, diesen Mangel durch eine neue Auflage zu beheben. Czermaks Werk steht in seiner Art einzig in der ophthalmologischen Literatur da; keine andere Nation hat ein ähnlich gediegenes Werk über die Augenoperationen aufzuweisen. Es ist mustergültig und vorbildlich für die Behandlung des Stoffes, durch die Vollständigkeit, durch die Klarheit der Darstellung und durch die scharfsinnige Kritik der einzelnen Verfahren, begruindet auf der genauen Analyse der Bedingungen und Ziele jeder Operation, welche oft in wirklich genialer Weise dargelegt werden. In diesem Sinne wird das Werk nie veralten, wenn auch manche der darin als gangbar geschilderten Operationsmethoden längst verlassen sein werden.

Czermak hätte mehr geschriehen, wenn nicht seine Lehrtätigkeit, an der er mit ganzer Seele hing, ihn so sehr in Anspruch genommen hätte. Den wertvollsten Teil seiner Zeit widmete er stets seiner Klinik; seine Schüler und nicht weniger seine Kranken wissen vor allen, was sie an ihm verloren haben, und ich selbst betrauere in Czermak einen treuen und aufrichtigen Freund.

\section{E. Fuchs.}

